This item was submitted to Loughborough's Research Repository by the author.

Items in Figshare are protected by copyright, with all rights reserved, unless otherwise indicated.

\title{
Supporting and developing engineering education in the UK and beyond
}

PLEASE CITE THE PUBLISHED VERSION

http://dx.doi.org/10.1109/ICL.2013.6644583

PUBLISHER

(c) IEEE

VERSION

AM (Accepted Manuscript)

LICENCE

CC BY-NC-ND 4.0

REPOSITORY RECORD

King, Melanie R.N., and Peter Willmot. 2019. "Supporting and Developing Engineering Education in the UK and Beyond". figshare. https://hdl.handle.net/2134/13679. 
This item was submitted to Loughborough's Institutional Repository (https://dspace.lboro.ac.uk/) by the author and is made available under the following Creative Commons Licence conditions.

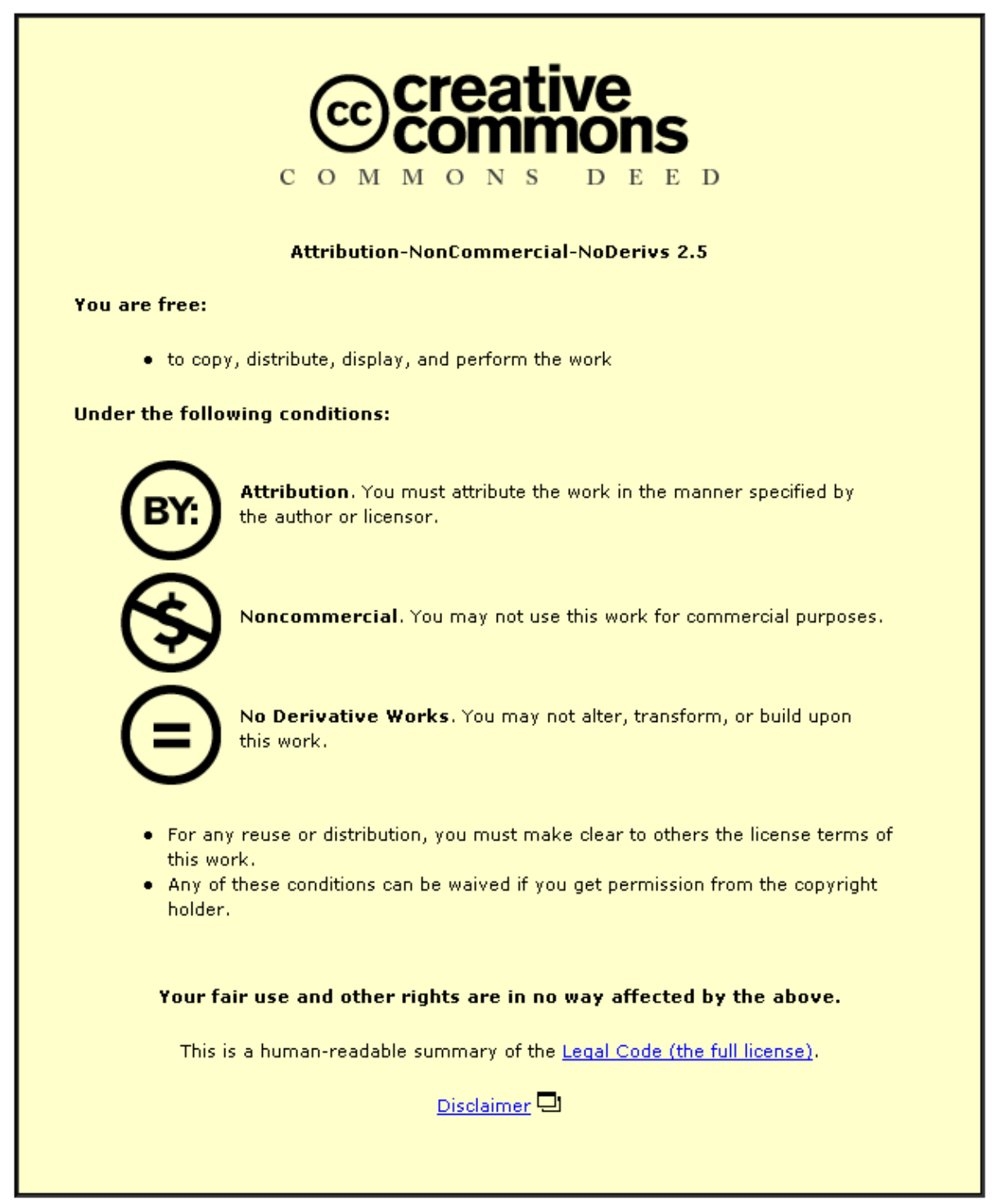

For the full text of this licence, please go to: http://creativecommons.org/licenses/by-nc-nd/2.5/ 


\section{Supporting and developing engineering education in the UK and beyond.}

\author{
Melanie King \\ Centre for Engineering and Design Education \\ Loughborough University \\ Loughborough, UK \\ M.R.N.King@lboro.ac.uk
}

\author{
Peter Willmot \\ School of Mechanical \& Manufacturing Engineering \\ Loughborough University \\ Loughborough, UK \\ P.Willmot@lboro.ac.uk
}

\begin{abstract}
This paper details the emergence and development of the 'Centre for Engineering and Design Education' (CEDE) at Loughborough University, UK, and provides ample evidence that such a Centre can prove to be a highly effective support mechanism for discipline-specific academics and can develop and maintain valuable national and international networks and collaborations along with considerable esteem for the host university. The CEDE is unique in the UK and has achieved considerable success and recognition within the local engineering education community and beyond. Here we discuss the historical background of the Centre's development, the context in which it operates, and its effective management and operation strategy. The success it has enjoyed is described through examples, with much evidence of the generation of a significant amount of external funding; the development of high quality learning spaces; learning technology systems, improvements in curriculum design; a strong record of research and publication on the pedagogy of engineering; strong links with industry and employers; and a wealth of connections and know-how built up over the years.
\end{abstract}

Keywords-Staff support, e-learning, pedagogic resaerch

\section{INTRODUCTION}

Although it was not the original intention, the Centre's influence gradually spread beyond the University, having widespread recognition of its achievements nationally and internationally both within higher education and industry. It is no accident that the CEDE has evolved at Loughborough University as the institution is at the geographic centre of the United Kingdom and has one of the largest faculties of engineering, with around 5000 staff and students divided into five Schools covering a broad range of engineering and design technology disciplines with an international reputation in many areas for both teaching and research. Published student guides consistently rank all Loughborough's engineering schools in the top ten of British Universities.

The Centre has amply demonstrated its impact and effectiveness in enhancing the learning experience of many thousands of students and of making a positive difference to the staff it supports within the engineering related schools. The impact of the learning technologies that have been developed in CEDE has been felt across other disciplines too. Furthermore, staff and associates of CEDE have disseminated their work widely at national and international conferences and through publications and by hosting workshops and events.

\section{THE EMERGENCE OF A FOCUS FOR ENGINEERING EDUCATION}

In 1997 the University invested in a small centre for engineering education named the Engineering Teaching \& Learning Support Centre (EngTLSC), by offering limited pump-priming funding. This Centre adopted an approach that was distinct from the more conventional support offered by the central university services, which continue to exist separately, by providing timely, subject-specific expertise at the point of need. Its modus operandi was to meet academics' needs directly, save them time and solve real problems of practicing teachers. This proved to be a highly effective and popular method of support.

Within a few years, the Centre had successfully gained major funding from several national teaching enhancement streams, namely the Teaching Quality Enhancement Fund (TQEF), the Fund for the Development of Teaching and Learning (FDTL) and the Teaching and Learning Technology Programme (TLTP). Significantly also, the team subsequently succeeded in a major competitive bid to host and establish the UK-Higher Education Academy (HEA) Engineering Subject Centre, which generated an annual income of around $£ 500,000$ (US\$800,000) per year between 2000 and 2010. Based at Loughborough University, its remit was to, "work in partnership with the learned UK engineering community to provide the best possible higher education learning experience for all students and contributing to the long term health of the engineering profession".

The University's internal Centre was rebranded as the Engineering Education Centre (EEC) in 2002 and was colocated with the national Subject Centre in a defined area of the campus. It continued to develop high quality outputs and tailored support, helping to enhance the University's first class reputation for teaching engineering, through close relationships with industrial partners and a proactive approach to teaching and learning. The team's success continued, when in 2004 the Higher Education Funding 
Council for England (HEFCE) awarded separate additional funding of over $£ 4 \mathrm{~m}$ (US\$6.2) to create the Engineering Centre for Excellence in Teaching and Learning (engCETL), based on the Loughborough campus, in recognition of the University's exceptional work in teaching engineering, its collaboration with industry to deliver a rich and relevant educational experience.. EngCETL was just one of a number of such centres funded around the country against competitive tenders but was the only centre specifically designed to support engineering.

In March 2005 the engCETL was established and within a year a bespoke space within a brand new building was designed by the team and built to house the new Centre with state-of-the-art teaching facilities, and co-existed with the HEA Engineering Subject centre for five years. New appointments, funded by the CETL programme, brought additional expertise and experience to the team in the form of learning technologists, pedagogic researchers, academic and industrial co-ordinators, educational consultants, six $\mathrm{PhD}$ studentships were funded in engineering education and, seven academics, seconded part-time from engineering and engineering and design schools, played an important liaison role, supervised the research students and participated in many of the projects.

The Centre was destined to regenerate itself once again in 2011, which saw the end of the major external funding initiatives from HEFCE and the considerable contraction of HEA activities. This included, nationally, the closure of all 24 'HEA Subject Centres'. Such was the perceived value, however that the CEDE, which is now funded locally by the university, has continued much of the good work that has gone before and is actively seeking external funding to support additional educational projects and staff in support of the HE community, building on the links forged in the last 15 years. The Centre now has around 10 staff, 3.9FTE of which are core funded by the University; the remainder through small short term external contracts, and CEDE's current strategy comprises three main aims:

- To support engineering and design academics to encourage effective and efficient practice as well as innovation

- To maintain the University's leading position in the delivery of high quality engineering and design education

- To support engineering and design students, with a particular focus on meeting the needs of industry.

\section{MANAGEMENT, OPERATION AND REVENUE FROM EXTERNAL FUNDING}

The management and operation of the CEDE is carried out by a management team and a steering group, specifically created to get operational input from academics and senior management as well as from students and representatives from industry and professional bodies.

The CEDE always aims to operate in the most direct way possible, this not only includes one-to-one support but more generally through development projects and guidance for busy academics including: over-the-phone advice; drop-in sessions; help with funding applications; a varied events programme and individualised projects. An annual call for projects invites academics in each School to submit ideas requiring support, development or research. A panel, consisting of the Centre's academic leader (Pro-Vice Chancellor) and academic associates from the Schools contribute ideas and make recommendations on the proposals. This panel ensures effective communication and transfer of practice across all of the engineering-related departments, to solve common problems and gain efficiencies by sharing resources and expertise. CEDE staff time to work on the projects is offered free of charge within the university.

The management team has a strong track-record for sourcing smaller but substantial external funding and managing the resulting projects. For example, in addition to the HEA Subject Centre and the CETL initiatives, between 2005 and 2008 around £365k (US\$570k) of Joint Information Systems Committee (JISC) funding was achieved through sole, joint and consortium projects. 'In kind' funding of US\$100k was secured from Hewlett Packard for the Design School to enhance research and teaching in digital design. Even during the current austere financial climate, during the academic year 20011/12, the team have successfully received nearly $£ 450$ k (US\$700) of external funding from the HE-STEM Programme, the HEA, JISC, the Engineering and Physical Sciences Research Council (EPSRC) and the Royal Academy of Engineering (RAEng) amongst others.

\section{BUILDING NATIONAL AND INTERNATIONAL CONNECTIONS}

The CEDE and its predecessors have gained a national and international reputation for excellence in supporting and delivering the advancement of engineering education. Two specific examples of outreach illustrate the quality of support. Firstly, CEDE administers a high quality, peer reviewed academic journal, started in 2006 by the Engineering Subject Centre - Engineering Education: Journal of the Higher Education Academy. Secondly, CEDE also administers the premier UK based International Engineering Education Conference Series on a biennial basis, which started in 2004. The 5th conference in the series (EE2012) took place in Coventry last September and attracted educators and pedagogic researchers from all over the world.

The Centre has strong links with the Royal Academy of Engineering, Engineering Council UK, Engineering Professors Council, professional institutions and engineering departments worldwide. The team has welcomed over 15 delegations of senior staff from overseas looking to redevelop their own institution's learning and teaching. Overseas visitors have participated in various workshops and seminars and subsequently repatriated a number of the learning tools and ideas to their own institutions.

The CEDE and its predecessors have gained a national and international reputation for excellence in supporting and delivering the advancement of engineering education. Two specific examples of outreach illustrate the quality of 
support. Firstly, CEDE administers a high quality, peer reviewed academic journal, started in 2006 by the Engineering Subject Centre - Engineering Education: Journal of the Higher Education Academy [4]. Secondly, CEDE also administers the premier UK based International Engineering Education Conference Series on a biennial basis, which started in 2004. The 5th conference in the series (EE2012) [5] will take place in Coventry this September and attracts educators and pedagogic researchers from all over the world.

The Centre has strong links with the Royal Academy of Engineering, Engineering Council UK, Engineering Professors Council, professional institutions and engineering departments worldwide. The team has welcomed over 15 delegations of senior staff from overseas looking to redevelop their own institution's learning and teaching. Overseas visitors have participated in various workshops and seminars and subsequently repatriated a number of the learning tools and ideas to their own institutions.

A series of twelve teaching guides, published as small booklets researched and published by the former engineering Subject Centre covering were the result of cooperation between Centre staff and experts drawn from the wider community throughout the UK. A wide variety of topics are covered, including; enhancing the first year experience, assessing creativity, personal tutoring (pastoral care) and working with international students. These publications [6] are now accessible through the HEA archive webpages or through CEDE.

\section{PEDAGOGIC RESEARCH}

CEDE activities are underpinned by research into the method and practice of teaching (pedagogic research) and draw upon literature as well as conducting rigorous evaluation of its activities and developments. While engineering education research is not generally well supported in the UK, the Centre is committed to facilitating this for academics at the University and by supporting cooperative ventures with other institutions. A varied programme to help develop the national engineering education research (EER) community has been delivered, including pedagogic research workshops and symposiums and providing funding for an EER Special Interest Group.

A recent development of CEDE is the Engineering and Design Education Network (EDEN series of short seminars which were started in 2011 to help maintain links within the HE community. Four separate EDEN events have taken place so far, all included external speakers from as far away as Australia. Topics covered have been collaborative learning, student engagement, employability and curriculum enhancement.

Outputs from research activities carried out by the CEDE community have been disseminated at national and international conferences, events and within peer-reviewed publications. Over 100 peer-reviewed outputs (including journal articles, conference papers and edited works) have been produced in the last 6 years by CEDE staff and those closely associated with it.

\section{INDUSTRIAL AND EMPLOYER LINKS}

The CEDE has been committed to supporting, enhancing and encouraging the involvement of industry in the design and delivery of curriculum and a significant amount of its work has been in this area. Strong foundations have been laid to enable relationships between employers and University staff to be built, benefiting students and strengthening Loughborough's reputation for employerlinked education.

The majority of engineering degrees at Loughborough include a lengthy placement in industry. The team led the production of a nationally available guide, 'Industrial Placements for Engineering Students: a Guide for Academics'. The team has also written another specialist guide entitled, 'The Involvement of Industry in Teaching: A Guide for Academics’ (2010). This guide contains 22 case studies of current industrial engagement.

Global industry needs graduates who have expertise in technical skills and in the application of complementary skills. The Centre has recently been active in disseminating the latest research in this area more widely through a Royal Academy of Engineering sponsored project, 'Engineering Graduates for Industry'[7] and the forthcoming publication of a 64 page guide to assist stakeholders in providing higher education for the 21st century and foster their own partnerships with industry.

Many academics who have worked with the Centre report that they would not have the time to follow up important initiatives, which enhance the student learning experience if it were not for the CEDE. For example, the Centre helped to facilitate and organise Loughborough's involvement with the UNITECH International Society's industrial placement and exchange programme [8].

\section{LEARNING TECHNOLOGY FOR CURRICULUM DEVELOPMENT}

The CEDE is renowned for producing high quality, evidence-based, bespoke teaching, learning and assessment resources and developing administrative tools that achieve real efficiencies, saving academics' time and lessening the administrative burden and enhancing the student learning experience. The project-led approach allows academics to develop their ideas within an inter-disciplinary team consisting of technologists, researchers and teachers, all of whom bring specialist knowledge and experience and, more importantly, time to explore the problem and come up with robust solutions.

Centre staff have the skills to develop technology that is built into institutional systems and a noteworthy example of this is the online system called Co-Tutor [9]. Originally conceived in 1998 in the Department of Electronic and Electrical Engineering, Co-Tutor started life as a simple system to help keep track of pastoral meetings with students but over the years and, taking into account feedback from academic users, its functionality has increased massively. Use of the online monitoring system slowly spread around 
the campus as it was found to be an invaluable aid for the monitoring of departmental tutor and tutee meetings for students on course, those on placement as well as postgraduate researchers. Co-tutor improves significantly the standard practice of keeping meeting notes and makes the frequency and quality of support, provided by staff for students, completely transparent to senior colleagues and department managers. It provides audit trails and accountability for the quality of care provided to students throughout their learning journey.

The Co-Tutor system contains important metrics on student welfare, progression and attendance. It is now recognised as an important collection of data regarding student welfare and the ability to view trends and mine the data is already being explored. Anecdotal evidence suggests it is already being used for research purposes. The innovation and impact of Co-Tutor was internationally recognised when it gained a global Leadership Award at the IMS (Global Learning Consortium) Learning Impact Conference in Long Beach, California, in 2010. Co-Tutor has also recently been recognised as an important tool for retention and success in a UK 'Compendium of Effective Practice' [10].

Some developed systems have been successfully exported outside the university. A major success of the CEDE legacy is an online system for peer-moderated marking, called WebPA. It started from a project proposed by a lecturer in the School of Mechanical and Manufacturing Engineering to enhance assessed group work. The research grounded, flexible system automatically moderates group marks for each student based on criteria supplied by the tutor and data entered by the students.

In 2006 the Centre gained a substantial grant from JISC to develop WebPA as an open source system available to any higher education institution (http://www.webpa.ac.uk). The project involved the collaboration of Loughborough University and the University of Hull. As a result, around 30 HEIs have implemented WebPA, including institutions in the USA and Australia. Starting out as a 'Special Interest Group' with small funding from the engineering Subject Centre, an active community of practice has evolved around the system with academics who are researching and developing peer assessment methods for marking and providing feedback to students. Findings from their research and updated or new code are fed back into the open source tool which benefits the whole community of users.

In 2008, the WebPA tool gained international recognition by winning a prestigious award at the IMS (Global Learning Consortium) Learning Impact Conference in Austin, Texas and was also named 'Best Assessment Support Tool'. It continues to evolve as an appropriate method for the peermoderated marking of group projects in any discipline and the wealth of numerical data it implicitly collects has provided a valuable resource for pedagogic researcher looking into peer assessment and feedback [e.g.11]. These examples are just two of the many topics addressed by CEDE and its ancestors through technology based solutions. Other projects have been wide-ranging covering, for example, a support system for students with disabilities and a system for planning and recording personal development. Administrative facilities have been developed to assist with the selection, allocation and monitoring of research projects and an online catalogue for laboratory equipment and specialist tools. Specialist learning resources have included virtual laboratories and an automated marking system for computer programming tasks, amongst others.

\section{CONCLUSIONS}

Having a focal point and outward reputation for excellence in discipline specific education puts a university in an enviable position to exploit funding opportunities, even in a generally difficult economic climate. The evidence suggests that success breeds more success here. The CEDE provides a strong knowledge conduit and outward brand that continues to develop local, national and international esteem in STEM education. There is good reason to believe that this process could be replicated in other countries, at another institution and maybe in different disciplines.

The Centre's achievements are down to: the many successes it has had in securing funding; building links within academia and industry; providing first class learning spaces, the skillful development of innovative learning technology and curriculum development based upon sound pedagogic research; and the connections and know-how that have been built up have proven absolutely invaluable to the host University and its influence can be felt through the connections that it has within the scholarly networks, professional and funding bodies and industry.

The CEDE welcomes visitors and research cooperation with academics and educational developers worldwide.

\section{References}

[1] The Guardian, University Guide Subject Tables, 2012, http://www.guardian.co.uk/education/series/universityguide-2013-subjects

[2] Loughborough University, Towards 2016 http://www.lboro.ac.uk/admin/policy/strategic_plan.pdf

[3] Times Higher Education, Student Experience Survey, 2006-2010

[4] Engineering Education: Journal of the Higher Education http://78.158.56.101/archive/engineering/journal

[5] International Conference on Innovation, Practice and Research in Engineering Education. http://cede.lboro.ac.uk/ee2012/

[6] Higher Education Academy, Archive site for the Engineering Subject Centre. Publications, Teaching Guides. http://84.22.166.132/guides.html

[7] Lamb, F,. et al., Royal Academy of Engineering, 'Engineering Graduates for Industry' February 2010 http://www.raeng.org.uk/education/scet/pdf/Engineering_gra duates_for_industry_report.pdf 
[8] UNITECH International, a network of professional possibilities. www.unitech-international.org/

[9] Loughborough University internal document, About Co-Tutor http://co-tutor.lboro.ac.uk/about.php

[10] Andrews, J, Clark, R and Thomas, L,. Compendium of effective practice in higher education retention and success, The Higher Education Academy. 2012. Available at http://www.heacademy.ac.uk/resources/detail/what-worksstudent-retention/Compendium_Effective_Practice

[11] Willmot, P. and Pond, K,. Multi-Disciplinary Peermark Moderation of Group Work, Learning and Teaching: International Journal of Higher Education, 1(1), pp.2-13, ISSN:

http://www.sciedu.ca/journal/index.php/ijhe/article/view/804 /528. DOI: 10.5430/ijhe.v1n1p2. 